\title{
Understanding and Applying Research Paradigms in Educational Contexts
}

\author{
Associate Professor Charles Kivunja ${ }^{1}(\mathrm{PhD})$ \& Associate Professor Ahmed Bawa Kuyini ${ }^{2}(\mathrm{PhD})$ \\ ${ }^{1}$ University of New England, Australia \\ ${ }^{2}$ United Arab Emirates University, United Arab Emirates \\ Correspondence: Associate Professor Charles Kivunja, (PhD), University of New England, Australia
}

Received: August 8, 2017

Accepted: September 1, 2017

Online Published: September 5, 2017

doi:10.5430/ijhe.v6n5p26

URL: https://doi.org/10.5430/ijhe.v6n5p26

\begin{abstract}
The concept of research paradigm is one that many higher degree research students, and even early career researchers, find elusive to articulate, and challenging to apply in their research proposals. Adopting an ethnographic and hermeneutic methodology, the present paper draws upon our experiences as lecturers in Research Methods over many years, and upon pertinent literature to explain the meaning of research paradigm. The paper elucidates the key aspects of research paradigms that researchers should understand well to be able to address this concept adequately in their research proposals. It offers suggestions on how researchers can locate their research into a paradigm and the justification needed for paradigm choice. With the explicit purpose of helping higher degree research (HDR) students design effective research proposals, the paper also discusses the different research methodologies best suited to conduct research in each of the paradigms discussed.
\end{abstract}

Keywords: Research paradigm, Epistemology, Ontology, Methodology, Axiology

\section{Introduction: What Do We Mean by Research Paradigm?}

A review of literature from leaders in the field leads to a deep understanding of the meaning of a research paradigm. For example, in The Structure of Scientific Revolutions American philosopher Thomas Kuhn (1962) first used the word paradigm to mean a philosophical way of thinking. The word has its aetiology in Greek where it means pattern. In educational research the term paradigm is used to describe a researcher's 'worldview' (Mackenzie \& Knipe, 2006). This worldview is the perspective, or thinking, or school of thought, or set of shared beliefs, that informs the meaning or interpretation of research data. Or, as Lather (1986) explains, a research paradigm inherently reflects the researcher's beliefs about the world that $\mathrm{s}$ /he lives in and wants to live in. It constitutes the abstract beliefs and principles that shape how a researcher sees the world, and how s/he interprets and acts within that world. When we say that it defines the researcher's worldview, we mean that a paradigm constitutes the abstract beliefs and principles that shape how a researcher sees the world, and how s/he interprets and acts within that world. It is the lens through which a researcher looks at the world. It is the conceptual lens through which the researcher examines the methodological aspects of their research project to determine the research methods that will be used and how the data will be analysed. Guba and Lincoln (1994) who are leaders in the field define a paradigm as a basic set of beliefs or worldview that guides research action or an investigation. Similarly, the gurus of qualitative research, Denzin and Lincoln (2000), define paradigms as human constructions, which deal with first principles or ultimates indicating where the researcher is coming from so as to construct meaning embedded in data. Paradigms are thus important because they provide beliefs and dictates, which, for scholars in a particular discipline, influence what should be studied, how it should be studied, and how the results of the study should be interpreted. The paradigm defines a researcher's philosophical orientation and, as we shall see in the conclusion to this paper, this has significant implications for every decision made in the research process, including choice of methodology and methods. And so a paradigm tells us how meaning will be constructed from the data we shall gather, based on our individual experiences, (i.e. where we are coming from). It is therefore very important, that when you write your research proposal for HDR, you clearly state the paradigm in which you are locating your research.

\section{What Are the Essential Elements of a Research Paradigm? Pertinent Literature}

According to Lincoln and Guba (1985), a paradigm comprises four elements, namely, epistemology, ontology, methodology and axiology. It is important to have a firm understanding of these elements because they comprise the 
basic assumptions, beliefs, norms and values that each paradigm holds. Therefore, in locating your research proposal in a particular research paradigm, the understanding is that your research will uphold, and be guided by the assumptions, beliefs, norms and values of the chosen paradigm. It is therefore important that you demonstrate that you know what each of these elements mean.

\subsection{Epistemology of a Paradigm}

Epistemology has its aetiology in Greek where the word episteme, means knowledge. Put simply, in research, epistemology is used to describe how we come to know something; how we know the truth or reality; or as Cooksey and McDonald (2011) put it, what counts as knowledge within the world. It is concerned with the very bases of knowledge - its nature, and forms and how it can be acquired, and how it can be communicated to other human beings. It focuses on the nature of human knowledge and comprehension that you, as the researcher or knower, can possibly acquire so as to be able to extend, broaden and deepen understanding in your field of research. Schwandt (1997) defines it as the study of the nature of knowledge and justification. And so, in considering the epistemology of your research, you ask questions like: Is knowledge something which can be acquired on the one hand, or, is it something which has to be personally experienced? What is the nature of knowledge and the relationship between the knower and the would-be known? What is the relationship between me, as the inquirer, and what is known? These questions are important because they help the researcher to position themselves in the research context so that they can discover what else is new, given what is known. And so to understand the epistemological element of your paradigm, you should ask the very important question of how we know what we know? This question is the basis for investigating 'truth'. Whereas it might be debatable as to whether there is such a thing as 'truth' (Davidson, 2000), if we take factual evidence as truth, then epistemology helps you to ask factual questions, such as how do we know the truth? What counts as knowledge? These are particularly important questions because one of the criteria by which higher degree research is judged is its contribution to knowledge. In trying to articulate the answers to the above questions, researchers can draw from four sources of knowledge. Those sources are intuitive knowledge, authoritative knowledge, logical knowledge, and empirical knowledge (Slavin, 1984). If you rely on forms of knowledge such as beliefs, faith, and intuition, then the epistemological basis of your research is intuitive knowledge. If you rely on data gathered from people in the know, books, leaders in organisations, then your epistemology is grounded on authoritative knowledge. If you put emphasis on reason as the surest path to knowing the truth, then this approach is called rationalist epistemology or logical knowledge. On the other hand, if you put emphasis on the understanding that knowledge is best derived from sense experiences, and demonstrable, objective facts, then your approach leans towards empirical epistemology. Epistemology is important because, it helps you to establish the faith you put in your data. It affects how you will go about uncovering knowledge in the social context that you will investigate.

\subsection{Ontology of a Paradigm}

Ontology is a branch of philosophy concerned with the assumptions we make in order to believe that something makes sense or is real, or the very nature or essence of the social phenomenon we are investigating (Scotland, 2012). It is the philosophical study of the nature of existence or reality, of being or becoming, as well as the basic categories of things that exist and their relations. It examines your underlying belief system as the researcher, about the nature of being and existence. It is concerned with the assumptions we make in order to believe that something makes sense or is real, or the very nature or essence of the social phenomenon we are investigating. It helps you to conceptualise the form and nature of reality and what you believe can be known about that reality. Philosophical assumptions about the nature of reality are crucial to understanding how you make meaning of the data you gather. These assumptions, concepts or propositions help to orientate your thinking about the research problem, its significance, and how you might approach it so as to contribute to its solution. Ontology is so essential to a paradigm because it helps to provide an understanding of the things that constitute the world, as it is known (Scott \& Usher, 2004). It seeks to determine the real nature, or the foundational concepts which constitute themes that we analyse to make sense of the meaning embedded in research data. It makes you ask questions such as: Is there reality out there in the social world or is it a construction, created by one's own mind? What is the nature of reality? In other words, Is reality of an objective nature, or the result of individual cognition? What is the nature of the situation being studied? Ontology enables you to examine your underlying belief system and philosophical assumptions as the researcher, about the nature of being, existence and reality. Philosophical assumptions about the nature of reality are crucial to understanding how you make meaning of the data you gather. These assumptions, concepts or propositions help to orientate your thinking about the research problem, its significance, and how you might approach it so as to answer your research question, understand the problem investigated and contribute to its solution. 


\subsection{Methodology of a Paradigm}

Methodology is the broad term used to refer to the research design, methods, approaches and procedures used in an investigation that is well planned to find out something (Keeves, 1997). For example, data gathering, participants, instruments used, and data analysis, are all parts of the broad field of methodology. In sum, the methodology articulates the logic and flow of the systematic processes followed in conducting a research project, so as to gain knowledge about a research problem. It includes assumptions made, limitations encountered and how they were mitigated or minimised. It focuses on how we come to know the world or gain knowledge about part of it (Moreno, 1947). In considering the methodology for your research proposal, you should ask yourself the question: How shall I go about obtaining the desired data, knowledge and understandings that will enable me to answer my research question and thus make a contribution to knowledge?

\subsection{Axiology}

Axiology refers to the ethical issues that need to be considered when planning a research proposal. It considers the philosophical approach to making decisions of value or the right decisions (Finnis, 1980). It involves defining, evaluating and understanding concepts of right and wrong behaviour relating to the research. It considers what value we shall attribute to the different aspects of our research, the participants, the data and the audience to which we shall report the results of our research. Put simply, it addresses the question: What is the nature of ethics or ethical behaviour? In answer to this question, it is important to consider your regard for human values of everyone that will be involved with or participate in your research project. This consideration is facilitated by the following questions. What values will you live by or be guided by as you conduct your research? What ought to be done to respect all participants' rights? What are the moral issues and characteristics that need to be considered? Which cultural, intercultural and moral issues arise and how will I address them? How shall I secure the goodwill of participants? How shall I conduct the research in a socially just, respectful and peaceful manner? How shall I avoid or minimise risk or harm, whether it be physical, psychological, legal, social, economic or other? (ARC, 2015).

Answers to these questions are best guided by four criteria of ethical conduct namely, teleology, deontology, morality and fairness (Mill, 1969). Technically, teleology is the theory of morality which postulates that doing what is intrinsically good or desirable, is a moral obligation that should be pursued in every human endeavour. And so, teleology refers to attempts made in research to make sure that the research results in a meaningful outcome that will satisfy as many people as possible. An application of this criterion is facilitated by questions such as, are the methods used in this research pragmatic and do they make common sense? Will the actions undertaken in the research produce more benefits than harm? Am I convinced that the actions that will be taken during the research will be the right ones? Have I considered all possible consequences of this research? Deontology is the understanding that every action that will be undertaken during the research will have its own consequence, intended to benefit participants, the researcher, the scholastic community or the public at large (Scheffler, 1982). It also allows for flexibility to deal with individual participants or observations. The morality criterion refers to the intrinsic moral values that will be upheld during the research. For example, that the researcher will be truthful in their interpretation of the data. Finally, the criterion of fairness draws the researcher's attention to the need to be fair to all research participants and to ensure that their rights are upheld. Implementation of this criterion is guided by questions such as, how fair will my research actions be? Will they treat all research participants in the same way? Will my actions show favouritism and/or discrimination towards any participants?

And so in the section on ethical considerations for your higher degree research proposal, you should demonstrate best ethical conduct by showing an understanding of what is right or wrong behaviour as you conduct the research. This consideration is founded on the understanding that all humans have dignity which must be respected, and they have a fundamental human right to make choices which you as a researcher must respect. Implementation of ethical considerations focuses on four principles which you need to uphold when dealing with your participants and data. These principles have the acronym PAPA namely: Privacy, Accuracy, Property, and Accessibility, and are briefly unpacked below, following Sidgwick, (1907) and Slote, (1985).

\subsubsection{Privacy}

Under this principle, you need to consider what information participants will be required to reveal to you or to others about themselves, their associations or organisations? It considers the conditions and safeguards under which data will be gathered and analysed. What things, for example, can participants keep to themselves, and not be forced to reveal to you or any other people? 


\subsubsection{Accuracy}

This principle considers who is responsible for the authenticity, fidelity, and, accuracy of information? Similarly, it considers how you as the researcher will cross-check with participants so they know you have recorded the data accurately. It also makes it very clear who will be held accountable for any errors in data? And, if any party were to be injured, how would they be compensated?

\subsubsection{Property}

Under this principle, you need to consider who will own the data? Will there be any payment for the data? If so, what will be the just and fair prices, for the exchange of data? Who will own the channels, such as publications and media through which information will be disseminated?

\subsubsection{Accessibility}

This principle considers who will have access to the data? How will the data be kept safe and secure? Under what conditions and with what safeguards will researchers and participants have access to the data? How will access to the data be gained?

\section{Why Has This Topic Attracted Controversy Among Researchers Over Time: Literature Review}

Both from evidence in the literature and from our experiences in supervising HDR students, it is clear to us that many HDR research students and early career researchers are often confused about the use of the term paradigm. At the broader level, this confusion stems from the use of the term paradigm in everyday discourses in contrast to its use in the educational research. Paradigm in everyday parlance does not include the qualities of epistemology, ontology, methodology or axiology, which, as we have seen above, are integral to the term in the field of research. It is therefore important for HDR students to be cognizant of this reality. What's more, there is also considerable diversity in how the term is used within research contexts. A review of research literature reveals that over the years, the term paradigm has conjured up considerable controversy (Guba, 1990). The controversy was in the main centred first of all, around the historical development of the term and how it was defined by various authors and secondly, by what became known as 'inter and intra-disciplinary power wars' or 'paradigm wars' in the social sciences (Lincoln \& Guba, 2000; Guba \& Lincoln, 2005), which were rampant especially in the 1980s.

An analysis of the definitions given by leaders in the field such as Guba and Lincoln (2005) and Creswell (1998; Creswell \& Miller, 2000) betrays a lack of agreement about what constitutes a paradigm as well as an overlap in definitions and explanations. For example, while Creswell's (1998) definition of a paradigm as “.... basic set of assumptions that guide their [researchers'] inquiries" (p. 74) aligns with the worldview perspective of a paradigm, Lincoln's (1990) definition (as alternative world views with such pervasive effects that ... permeates every aspect of a research inquiry) goes beyond this and encapsulates other perspectives of paradigm without being specific. This considerable and glaring overlap of definitions and/or explanations has to do, in part, with the fact that social behaviour is fluid and how we think or behave cannot be completely compartmentalised with clear-cut boundaries. As such, to think about a paradigm as a worldview or epistemological stance does not preclude the cross-over of ideas. Thus, no matter the position we start from, how we know and go about knowing is linked, or overlaps and affects how we conceive and explain paradigms. This is a major contributor to the confusion in the social sciences that HDR students and early career researchers experience in trying to articulate what constitutes the research paradigm for their projects.

The controversy in relation to the historical development has to do with Kuhn's (1962) original use and explanations of the term in his early work and how researchers in different fields of study came to understand and use the term. For example, Morgan (2007) asserts that the social scientists' use of the term differs from that in science studies. He argues that Kuhn's initial articulation of the notion of paradigm was confusing and culminated in the term being used by researchers in the field of science studies to mean "the consensual set of beliefs and practices that guide a field...." (Morgan, 2007, p. 49). At the same time the term has been used in social science research in about 3-4 different ways. These include that a paradigm means a worldview, a paradigm is an epistemological stance, a paradigm is a set of shared beliefs among members of a specialty area and, a paradigm as a model example of research (Morgan, 2007).

In casting a paradigm as a worldview, Morgan (2007, p. 49) presents the term as “.... all-encompassing ways of experiencing and thinking about the world, including beliefs about morals, values, and aesthetics". This all-encompassing position could mean that researchers might question what can be researched or whether at all some topics should be researched on moral grounds. Such a position could be useful in directing ethics and ethical decision-making within research, which aligns with questions about axiology. But it might also be restrictive in terms of the human desire to explore and understand our world. Therefore this view of a paradigm could potentially 
be a source of confusion, de-motivation or incoherence for HDR students.

The interpretation of paradigms as epistemological stances has its roots in the meaning of epistemology, which, as we saw above, relates to the questions about what does it mean to know and how can we know? Therefore this view of paradigm, takes the position that research inherently involves epistemological issues about the nature of knowledge and knowing. In this sense, researchers will align their notion of paradigm with the most popular epistemological stances (e.g., realism and constructivism) as distinctive belief systems (Morgan (2007). Researchers who are guided by either stance are directed by that position to ask particular type of research questions and also answer them in a particular way. The interpretation of paradigms as shared beliefs among members of a specialty area focuses on what members of a particular field of research think are the fundamental principles that govern research. Additionally, an analysis of a paradigm as a model example of research draws on the notion that paradigms are models about how research is done in a given field (Kuhn, 1970, Morgan, 2007). With such a diverse sense of what constitutes a paradigm, it is not surprising that HDR students and early career researchers experience difficulties in understanding paradigms and choosing one for their research.

In terms of the 'inter and intra-disciplinary power wars', the issue under consideration was about who had the power to name and define a paradigm. In this regard, key personalities in particular disciplines have over time sought to 'create' and 'add' new paradigms, which were often challenged or dismissed by colleagues and cross-disciplinary researchers. For example in the late 1990s, the field of special education saw the emergence of a 'new' tradition of research into special educational needs, which Skidmore (1996) called an 'organizational paradigm'. While some in the special needs field (e.g Avramidis \& Smith, 1999) accepted this as a new paradigm, other researchers in the social sciences did not agree with Skidmore's new paradigm. This raised the question about who had the power to name and keep a paradigm? In this regard, Morgan (2007, p. 61) writes “.....paradigms in social science research methodology are not abstract entities with timeless characteristics; instead, what counts as a paradigm and how the core content of a paradigm is portrayed involves a series of ongoing struggles between competing interest groups" . This conclusion endorses the reality of the inter-and intra-disciplinary power wars and is buttressed by the many 'new' paradigms that have been added to the list of social science research paradigms in the last two decades. Despite this complexity in the history of paradigm development, there is now general agreement about the major paradigms that are applicable in educational research, and we turn to these, in the following section.

\section{Which Are the Dominant Research Paradigms Applied in Educational Research?}

A large number of paradigms have been proposed by researchers but Candy (1989), one of the leaders in the field, suggests that they all can be grouped into three main taxonomies, namely Positivist, Interpretivist, or Critical paradigms. However, other researchers such as Tashakkori and Teddlie (2003a; 2003b) propose a fourth that borrows elements from these three and is known as the Pragmatic paradigm. Let's have a brief look at each of these.

\subsection{Positivist Paradigm}

First proposed by a French philosopher, Auguste Comte (1798 - 1857), the Positivist paradigm defines a worldview to research, which is grounded in what is known in research methods as the scientific method of investigation. Comte (1856) postulated that experimentation, observation and reason based on experience ought to be the basis for understanding human behaviour, and therefore, the only legitimate means of extending knowledge and human understanding. In its pure form, the scientific method, involves a process of experimentation that is used to explore observations and answer questions, as illustrated in Figure 1. It is used to search for cause and effect relationships in nature. It is chosen as the preferred worldview for research, which tries to interpret observations in terms of facts or measurable entities (Fadhel, 2002). Research located in this paradigm relies on deductive logic, formulation of hypotheses, testing those hypotheses, offering operational definitions and mathematical equations, calculations, extrapolations and expressions, to derive conclusions. It aims to provide explanations and to make predictions based on measurable outcomes. Those measurable outcomes are undergirded by four assumptions that Cohen, Manion and Morrison (2000), explain are determinism, empiricism, parsimony and generalizability. An unpacking of each of these assumptions helps researchers understand better the meaning and expectations of research conducted within this paradigm. Briefly, the assumption of determinism means that the events we observe are caused by other factors. Therefore, if we are to understand casual relationships among factors, we need to be able to make predictions and to control the potential impacts of the explanatory factors on the dependent factors. The assumption of empiricism means that for us to be able to investigate a research problem, we need to be able to collect verifiable empirical data, which support the theoretical framework chosen for your research and enable you to test the hypotheses you formulated. In assuming parsimony, the Positivist paradigm refers to the researcher's attempts to explain the phenomena they study in the most economic way possible. Finally, the generalizability assumption tells us that the 
results obtained from a research project conducted within the Positivist paradigm, in one context, should be applicable to other situations by inductive inferences. This means that the positivist researcher should be able to observe occurrences in the particular phenomenon they have studied, and be able to generalise about what can be expected elsewhere in the world. Because of these assumptions, the Positivist paradigm advocates the use of quantitative research methods as the bedrock for the researcher's ability to be precise in the description of the parameters and coefficients in the data that are gathered, analysed and interpreted, so as to understand relationships embedded in the data analysed.

And so, in terms of the four foundational elements or assumptions of a paradigm, for the Positivist paradigm, its epistemology is said to be objectivist, its ontology naive realism, its methodology experimental, and its axiology beneficence. Again, unpacking each of these elements should help the researcher understand better this paradigm. The objectivist epistemology holds that human understanding is gained through the application of reason (Fadhel, 2002). This implies that through research we can acquire knowledge which increasingly approximates the real nature of what it is that we investigate. In other words, through research, we can gain knowledge which helps us to become more objective in understanding the world around us. The naïve realist ontology assumes the acceptance of the following five beliefs (Putnam, 2012; Searle, 2015):

- There exists a world of material objects.

- Some statements about these objects can be known to be true through sense-experience.

- These objects exist whether they are actually perceived or even when they are not perceived. These objects of perception are assumed to be largely perception-independent.

- These objects are also able to retain properties of the types we perceive them as having, even when they are not being perceived. Their properties are perception-independent.

- By means of our senses, we perceive the world directly, and pretty much as it is. In the main, our claims to have knowledge of it are justified.

The experimental methodology element means that the research will involve manipulation of one variable to determine whether changes in that variable cause changes in another variable (Smith \& Heshusius, 1986). The former variable is called the explanatory or predictor variable, and the latter variable, is called the explained or dependent variable (Burns, 2000). This methodology can only apply if we are able to control what happens to the variables or subjects we study. Such control enables the researcher to test and to accept or reject hypotheses. The beneficence axiology refers to the requirement that all research should aim at maximizing good outcomes for the research project, for humanity in general, and for the research participants (Mertens, 2015). It also implies that the research should aim at avoiding or at least minimizing any risk, harm, or wrong that could occur during the research.

\subsubsection{Characteristics of Research Located Within The Positivist Paradigm}

The following summary should help you to understand the basic characteristics of research that is normally located within the Positivist paradigm (Neurath, 1973; Fadhel, 2002)

- A belief that theory is universal and law-like generalisations can be made across contexts.

- The assumption that context is not important

- The belief that truth or knowledge is 'out there to be discovered' by research.

- The belief that cause and effect are distinguishable and analytically separable.

- The belief that results of inquiry can be quantified.

- The belief that theory can be used to predict and to control outcomes

- The belief that research should follow the Scientific Method of investigation

$\circ$ Rests on formulation and testing of hypotheses

- Employs empirical or analytical approaches

- Pursues an objective search for facts

- Believes in ability to observe knowledge.

- The researcher's ultimate aim is to establish a comprehensive universal theory, to account for human and social behaviour.

- Application of the scientific method (Illustrated in Figure 1) 


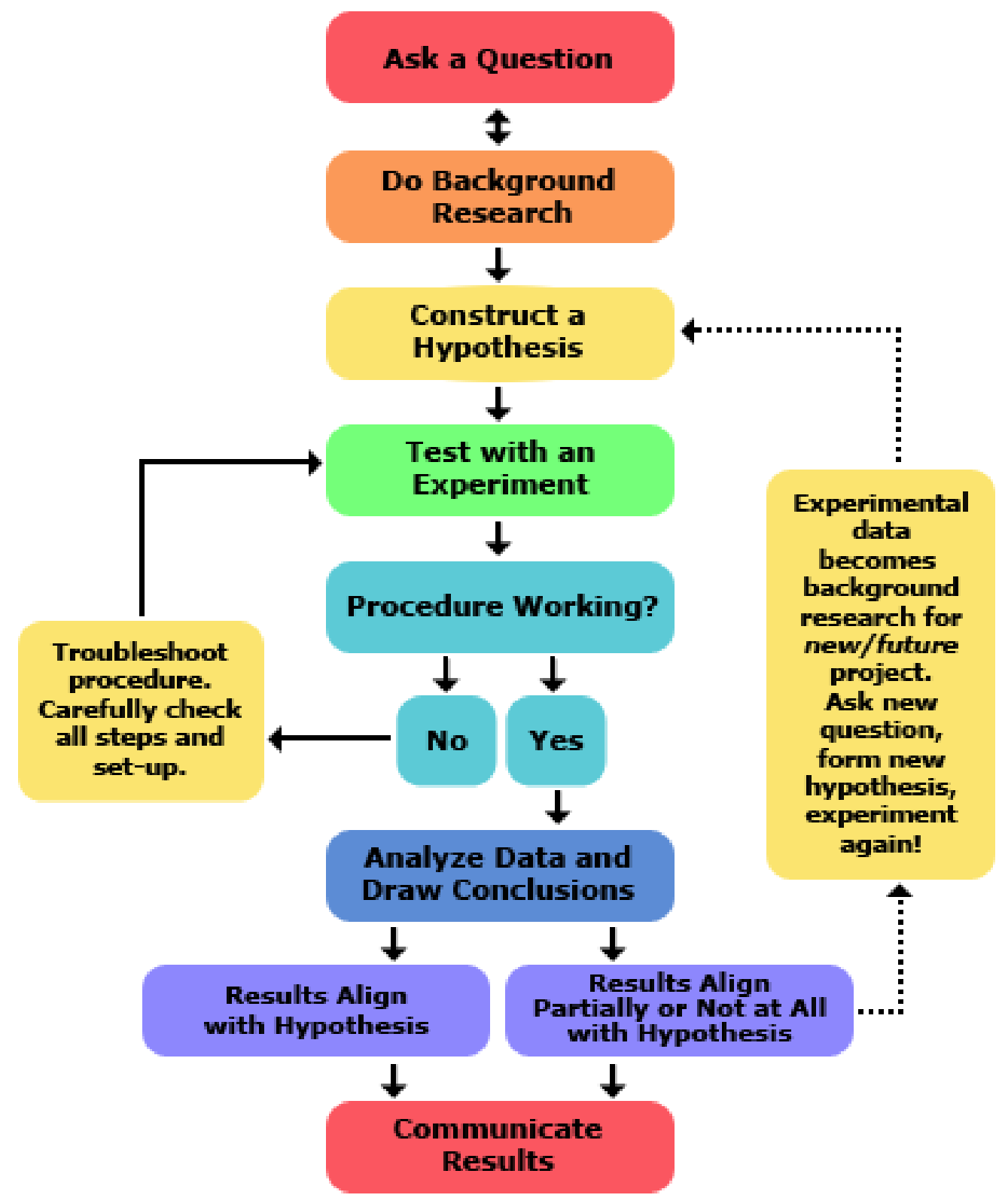

Figure 1. The Scientific Method

Source:

https://www.sciencebuddies.org/engineering-design-process/engineering-design-compare-scientific-method.shtml

As researchers wrestled with the understanding that many of these characteristics cannot be fully applied in contexts where humans are involved; that the social world cannot be studied in the same way as the natural world, that the social world is not value free and that it is not possible to provide explanations of a causal nature, modifications were made to relax some of the assumptions outlined above. This led to a derivative of this paradigm, known as the Postpositivist paradigm. The latter accepts that reality is imperfect and that truth is not absolute but probable. It allows for observations without experimentation or formulation of hypotheses to be tested. Guba (1990) says that whereas the Positivist paradigm maintains the belief that reality is out there to be studied, captured and understood, the Postpositivist cousin accepts that reality can never be fully understood; but at best, only approximated. Accordingly, the Postpositivist paradigm has tended to provide the worldview for most research conducted on human behaviour typical of educational contexts. 


\subsubsection{Criteria for Validating Research Located in the Positivist Paradigm}

The Positivist paradigm is usually validated by applying four criteria namely, internal validity, external validity, reliability, and objectivity (Burns, 2000). We explain, briefly, what each means and involves. Internal validity is the extent to which the results obtained in a study are attributable to the independent variable that explains their occurrence and not some other factors. This criterion helps us to answer some important questions. For example, are we able to say for certain that the changes in the independent variable are indeed responsible for the variations we have observed in the dependent variable? Furthermore, are we satisfied that the variation in the dependent variable might not be attributable to some other causes? Additionally, how confident are we that the changes we have obtained in the dependent variable are actually caused by the independent variable studied? Do we have enough evidence to conclude that changes in the independent variable explain the changes we observed in the dependent variable? Answers to these questions are important because, only if the results of our data analysis show that there is a high degree of internal validity are we entitled to make the claim that the analysis has identified cause and effect relationships. If the data analysis yielded low internal validity, then we would have no basis for claiming causality and we would have to conclude that there is little or no evidence of causality. Internal validity therefore defines the extent to which we are able to eliminate confounding variables within the study. In contrast, external validity refers to the degree to which the results obtained in a study can be generalized to other contexts (Prochaska, F. 2017). This is often an indication that our data were drawn from a sample that is representative of the population. It helps us to answer the question, based on the results of our study, are we able to say that the same thing happens or would happen in another or other settings? And so, if the results of our research can readily be generalised to the population at large, then we say that we can legitimately say that our results have a high level of external validity. Reliability is the degree to which a research instrument produces stable or consistent results (Kirk \& Miller, 1986). According to Joppe $(2000$, p. 1) reliability is defined as "the extent to which results are consistent over time. ... an accurate representation of the total population under study is referred to as reliability and if the results of a study can be reproduced under a similar methodology, then the research instrument is considered to be reliable". In everyday language the term is used to mean consistency or repeatability of measurement. Objectivity in research is quite a broad criterion. It refers to the degree to which you, as the researcher, utilise precise instruments, approach the research without bias, and with honesty, and remain open to suggestions from participants in the research (Myrdal, 1969). In research methods, objectivity means that all sources of bias are minimized and that personal or subjective ideas are eliminated as humanly possible. In the strict positivist sense, this criterion requires that as far as possible, you, the researcher, should remain distanced from what you study so that the findings of your research will depend on the nature of the data rather than on your preferences, personality, beliefs and values.

\subsection{The Interpretivist Paradigm/Constructivist Paradigm}

The central endeavour of the Interpretivist paradigm is to understand the subjective world of human experience (Guba \& Lincoln, 1989). This approach makes an effort to 'get into the head of the subjects being studied' so to speak, and to understand and interpret what the subject is thinking or the meaning s/he is making of the context. Every effort is made to try to understand the viewpoint of the subject being observed, rather than the viewpoint of the observer. Emphasis is placed on understanding the individual and their interpretation of the world around them. Hence, the key tenet of the Interpretivist paradigm is that reality is socially constructed (Bogdan \& Biklen, 1998). This is why sometimes this paradigm has been called the Constructivist paradigm. In this paradigm, theory does not precede research but follows it so that it is grounded on the data generated by the research act. Hence, when following this paradigm, data are gathered and analysed in a manner consistent with grounded theory (Strauss \& Corbin, 1990). This paradigm assumes a subjectivist epistemology, a relativist ontology, a naturalist methodology, and a balanced axiology. These elements are briefly explained below.

The assumption of a subjectivist epistemology means that the researcher makes meaning of their data through their own thinking and cognitive processing of data informed by their interactions with participants. There is the understanding that the researcher will construct knowledge socially as a result of his or her personal experiences of the real life within the natural settings investigated (Punch, 2005). There is the assumption that the researcher and their subjects are engaged in interactive processes in which they intermingle, dialogue, question, listen, read, write and record research data. The assumption of a relativist ontology means that you believe that the situation studied has multiple realities, and that those realities can be explored and meaning made of them or reconstructed through human interactions between the researcher and the subjects of the research, and among the research participants (Chalmers, Manley \& Wasserman, 2005). In assuming a naturalist methodology the researcher utilises data gathered through interviews, discourses, text messages and reflective sessions, with the researcher acting as a participant observer 
(Carr \& Kemmis, 1986). A balanced axiology assumes that the outcome of the research will reflect the values of the researcher, trying to present a balanced report of the findings.

\subsubsection{Characteristics of Research Located within the Interpretivist Paradigm}

According to Lincoln and Guba (1985), and Morgan, (2007), research conducted under the Interpretivist paradigm usually exhibits the following characteristics:

- The admission that the social world cannot be understood from the standpoint of an individual.

- The belief that realities are multiple and socially constructed

- The acceptance that there is inevitable interaction between the researcher and his or her research participants

- The acceptance that context is vital for knowledge and knowing.

- The belief that knowledge is created by the findings, can be value laden and the values need to be made explicit

- The need to understand the individual rather than universal laws.

- The belief that causes and effects are mutually interdependent.

- The belief that contextual factors need to be taken into consideration in any systematic pursuit of understanding.

\subsubsection{Criteria Used to Validate Research Located within the Interpretivist Paradigm}

Guba (1981) suggests that in research conducted within the Interpretivist paradigm the positivist criteria of internal and external validity, and reliability discussed above, should be replaced with four criteria of trustworthiness and authenticity. These include are credibility, dependability, confirmability and transferability. Although these criteria were initially challenged (Lincoln, 1995), they are now well accepted by many scholars in educational research (e.g. Merriam, 1998; Erlandson et al., 1993; Silverman, 2000; Bouma \& Atkinson, 1995) and so HDR students should be familiar with their meanings, which are outlined here.

The criterion of credibility is used in research located within the Interpretivist paradigm to refer to the extent to which data and data analysis are believable, trustworthy or authentic (Guba, 1981). This criterion should be used in research located within the Interpretivist paradigm in preference to the criterion of internal validity of the Positivist paradigm. In agreement with Guba (1981), Merriam (1998) explains that this criterion relates to the researcher's ability to investigate the question: How do the findings align with reality as constructed by the researcher and the research participants? Guba (1981) suggests that the criterion of dependability should be used in interpretivist research in preference to the criterion of reliability of the Positivist paradigm. Guba (1981) explains that this criterion refers to the ability of observing the same outcome or finding under similar circumstances. Whereas research located within the Positivist paradigm can utilise research methods which can demonstrate that if activities were repeated, in the same context and with the same methods and research participants we could achieve similar findings, Guba argues that because the interpretivist researcher deals with human behaviour which is by its very nature continuously variable, contextual, and subject to multiple interpretations of reality, s/he is not able to reproduce exactly the same results. At best, the researcher can make inferences which in themselves are influenced by the researcher's own construction of meaning. Those inferences and interpretation are dependable depending on the researcher's ability and skills to make sure that the findings truly emerge from the data gathered and analysed for the research. The criterion of confirmability is used by the interpretivist researcher in preference to the criterion of objectivity, which is applied by the positivist researcher (Guba, 1981). It refers to the extent to which the findings of your research project can be confirmed by others in the field. The overriding goal of this criterion is to ensure that your biases are minimised, and preferably eliminated, from contaminating the results of the data analysed. Shenton, (2004, p. 72) explains that for the research to achieve this criterion, "steps must be taken to help ensure as far as possible that the work's findings are the result of the experiences and ideas of the informants, rather than the characteristics and preferences of the researcher". The criterion of transferability is used in interpretivist research in preference to the criterion of external validity used in the Positivist paradigm (Guba, 1981). Lincoln and Guba (1985) explain that this criterion represents the researcher's efforts to ensure that they provide enough contextual data about their research so that readers of their findings can relate those findings to their own contexts. More than 35 years since Guba (1981) first proposed this criterion, it is still subject to considerable controversy. For example, Erlandson et al. (1993), like Gomm, Hammersley and Foster (2000) argue that since by definition, interpretivist research is context-specific, with 
regard to locale and participants, generalizability of the findings of research conducted within the Interpretivist paradigm is practically impossible.

\subsection{The Critical Paradigm/Transformative Paradigm}

The Critical paradigm situates its research in social justice issues and seeks to address the political, social and economic issues, which lead to social oppression, conflict, struggle, and power structures at whatever levels these might occur. Because it seeks to change the politics so as to confront social oppression and improve the social justice in the situation, it is sometimes called the Transformative paradigm. This paradigm assumes a transactional epistemology, (in which the researcher interacts with the participants), an ontology of historical realism, especially as it relates to oppression; a methodology that is dialogic, and an axiology that respects cultural norms.

\subsubsection{Characteristics of Research Located within the Critical Paradigm}

Following Guba and Lincoln (1988), as well as Mertens (2015) we can attribute the following characteristics to research conducted within the Critical paradigm.

- The concern with power relationships set up within social structures.

- The conscious recognition of the consequences of privileging versions of reality

- The respect for cultural norms

- An examination of conditions and individuals in a situation, based on social positioning.

- The treatment of research as an act of construction rather than discovery.

- A central focus of the research effort on uncovering agency, which is hidden by social practices, leading to liberation and emancipation.

- And endeavour to expose conjunctions of politics, morality, and ethics.

- The deliberate efforts of the researcher to promote human rights, and increase social justice, and reciprocity.

- The deliberate efforts of the researcher to address issues of power, oppression and trust among research participants

$\circ$ A high reliance on praxis.

- The use of ethnomethodology, situating knowledge socially and historically

- An application of action research

- The utilisation of participatory research.

\subsection{The Pragmatic Paradigm}

This Paradigm arose among philosophers who argued that it was not possible to access the 'truth' about the real world solely by virtue of a single scientific method as advocated by the Positivist paradigm, nor was it possible to determine social reality as constructed under the Interpretivist paradigm. For them, a mono-paradigmatic orientation of research was not good enough. Rather, these philosophers (such as Alise \& Teddlie, 2010; Biesta, 2010; Tashakkori and Teddlie, 2003a, and 2003b; Patton, 1990) argued that what was needed was a worldview which would provide methods of research that are seen to be most appropriate for studying the phenomenon at hand. So, these theorists looked for approaches to research that could be more practical and pluralistic approaches that could allow a combination of methods that in conjunction could shed light on the actual behaviour of participants, the beliefs that stand behind those behaviours and the consequences that are likely to follow from different behaviours. This gave rise to a paradigm that advocates the use of mixed methods as a pragmatic way to understand human behaviour - hence Pragmatic paradigm. So, as explained briefly in the brackets, this paradigm advocates a relational epistemology (i.e. relationships in research are best determined by what the researcher deems appropriate to that particular study), a non-singular reality ontology (that there is no single reality and all individuals have their own and unique interpretations of reality), a mixed methods methodology (a combination of quantitative and qualitative research methods), and a value-laden axiology (conducting research that benefits people).

\subsubsection{Characteristics of Research Located within the Pragmatic Paradigm}

In a sense, this paradigm was developed in an effort to put an end to the two diametrically opposed positions of the Positivist (and postpositivist) on one side and the Interpretivists on the other, and thus end what were referred to as 'Paradigm Wars' (Gage, 1989). Drawing on the work by Creswell (2003), Tashakkori and Teddlie (2003a); Patton (1990), and Mertens (2015), research located within this paradigm demonstrates the following characteristics: 
- A rejection of the positivist notion that social science inquiry can uncover the 'truth' about the real world.

- An emphasis of 'workability' in research.

- The use of 'what works' so as to allow the researcher to address the questions being investigated without worrying as to whether the questions are wholly quantitative or qualitative in nature.

- Adoption of a worldview that allows for a research design and methodologies that are best suited to the purpose of the study.

- Utilising lines of action that are best suited to studying the phenomenon being investigated.

- A rejection of the need to locate your study either in a Positivist (postpositivist) paradigm or an Interpretivist (constructivist) paradigm.

- Seeking to utilise the best approaches to gaining knowledge using every methodology that helps that knowledge discovery.

- Choice of research methods depending on the purpose of the research.

- A search for useful points of connection within the research project that facilitate understanding of he situation.

\section{What Are the Methodological Implications of Paradigm Choice?}

In this section of the paper, we address a cardinal question that HDR students often find perplexing, namely: having decided to locate my research in a particular paradigm, which methodology shall I use? Alternatively, what are the methodological implications of paradigm choice? This question was stated by Guba and Lincoln (1988) as: Do different inquiry paradigms imply different inquiry methodologies?

A very important relationship exists between paradigm and methodology because the methodological implications of paradigm choice permeate, the research question/s, participants' selection, data collection instruments and collection procedures, as well as data analysis. For example, in respect of data analysis, the choice of the Positivist paradigm means that the data to be gathered will be quantitative in nature, and are most likely to be analyzed using quantitative procedures. In contrast, choice of the Interpretivist paradigm aligns with research methodologies and methods that will gather and analyze qualitative data. For example, narrative approaches to data analysis are based on the social constructionist school of thought (Polkinghorne, 1988) and in telling a story or narrative, a person is able to describe the moral and ethical choices that they have made. The process has the potential to transform the person's experiences. In this process the data are critically analysed in terms of the historical, social and cultural context of the story and allow the researcher to examine the existing discourses and the issue of power (Foucault, 1982; 1987).

In many instances where the Interpretivist paradigm is chosen, data gathering methods follow a grounded theory approach, which is well suited to generating a theory from real life occurrences in which the social processes and what they mean are explained. It is based on symbolic interactionist theory (Strauss \& Corbin, 1990), and in some studies, the symbols or symbolism within the data provide basis for theorizing, about the participant experiences being investigated, their behaviours, responses, processes and the meanings embedded in these. Another example that helps to elucidate the link between paradigm choice and methodology can also be drawn from research located in the Interpretivist paradigm and seeking to discover the 'essence' of participants' experience in a context. Such research often asks the question 'what is it like to have that experience?' Therefore, phenomenology becomes the ideal methodology to apply in that research. Phenomenology would be the ideal methodology to apply in this case, because as Taylor and Bogdan, (1984) say, data analysis in such a research project focuses on the social constructionist principle that "what people say and do (is) a product of how they define their world" (pp. $8-9$ ). Phenomenology would therefore be the suitable methodology because this principle means that how people define their world is related to 1) the interactions they have with others, 2) how they perceive others to perceive them, 3) the ways in which they have learned to deal with life experiences and 4) the amount of perceived control they have, and 5) the significance of perceived control to them.

Another example, again taken from choice of the Interpretivist paradigm helps to illuminate the relationship between paradigm and methodology choice. For example, in trying to understand teachers' experiences of participation in the decision-making process in a school one could very well choose the Interpretivist paradigm. As we saw earlier, this paradigm's ontology assumes that there is no single reality. This position will require an epistemology that allows for the interpretation of the participants' perceptions of their own realities. In this case, an interpretivist epistemology would be ideal because it undergirds the fact that meaning or knowledge is not there to be discovered but individually or socially constructed. This paradigm tells us that people make their own reality by the meanings and 
interpretations they give to their experiences and that there are multiple truths. In essence reality is a result of our own making (Furlong, 2013). From this paradigmatic understanding, you would ask yourself the questions, how can I know the participants' world or experiences, or how can I gain knowledge of their perceptions of their experiences? The search for the answers to these questions about the process of how the participants experience their world, will constitute the methodology that you will use. And it becomes obvious that the 'how' will imply who should be invited to share their experiences, and how should they share those experiences? It will require you to consider how you will gather and store the data, analyse them, and how you would evaluate and interpret the participants' experiences, as embedded in your research data. In answering these questions, experience of the world or events, (which is unique to each one of us), remains the core of your data analysis and interpretation. This implies that a suitable methodology that could guide this kind of research would be phenomenology. This is because, a key component of phenomenology is the description of peoples' experiences (Moustakas, 1994, as cited in Creswell, 2007) and therefore as a research design, this methodology would be ideal because it seeks to understand, describe, and interpret human behaviour and the meaning individuals make of their experience" (Carpenter, 2013, p. 117).

Another illustration of the link between paradigm choice and methodology, is taken from the field of special education. For example, writing about implications of paradigm choice for special education research, Avramidis and Smith (1999. p. 32) said:

Special education research using the interpretivist paradigm will require that the researcher will not consider the 'label' or 'syndrome' as a concept, which is unitary and valid across individuals and contexts. .... Instead the perceptions of teachers, learning support assistants, SENCO's, parents and the children - young adults themselves will be sought in order to gain a better understanding of the particular needs of the given individual.

Here again we see that the paradigm chosen influences what will constitute trustworthy data and how the data will be analysed. It can be seen that when a study is interpretivist in nature, and seeking to understand the experiences of a broad range of stakeholders, ability to interpret their experiences becomes an important methodological consideration.

Thus, while it is not possible within the scope of this paper to go into details of what each research methodology entails, the following subsections provide a snapshot of research methodologies researchers mostly use in the different paradigms.

\subsection{Research Methodologies Suited to the Positivist Paradigm}

The research conducted under the Positivist paradigm often utilises the following methodologies.

- Experimental methodology

- Quasi-experimental methodology

- Correlational methodology

- Causal comparative methodology

- Randomized control trials methodology

- Survey research methodology

\subsection{Research Methodologies Suited to the Interpretivist Paradigm}

For research conducted under the Interpretivist paradigm, researchers have a wide choice of methodologies including:
○ Naturalist methodology
- Narrative inquiry methodology
- Case study methodology
○ Grounded theory methodology
- Phenomenology methodology
○ Hermeneutics methodology
- Ethnography methodology
- Phenomenography methodology
- Action research methodology 
- Heuristic inquiry methodology

\subsection{Research Methodologies Suited for Use in the Critical Paradigm}

Many research projects conducted under the Critical paradigm apply the following methodologies.

$\circ$ Neo-Marxist methodology
$\circ$ Feminist theories
$\circ$ Cultural studies
$\circ$ Critical race theory
$\circ \quad$ Freirean studies
$\circ$ Participatory emancipation
$\circ \quad$ Postcolonial/indigenous methodology
$\circ \quad$ Queer theory
$\circ \quad$ Disability theories
$\circ \quad$ Action research

As explained earlier, the Critical paradigm is suited to studies about social justice and giving voice to the voiceless or those less powerful. In educational research, one of the areas that easily fits this type of research is the field of special education. Using people with disabilities as researchers or research assistants allows for developing knowledge and skills about their own conditions or experiences. The Critical paradigm is interested in empowerment and removing oppressive structures around research subjects. Therefore, as shown above, action research is one methodology that could be used well within this paradigm. This is because the application of action research would be one way of ensuring that the power difference between the expert or researcher, with so much power (knowledge, expertise and other resources), is minimised against relatively powerless research subjects. This change would align well with the paradigm's emancipatory worldview and lead to social transformation. Thus, when applied in the field of special education, this could lead to empowerment. According to Barnes (1992) such an approach allows researchers to learn how to put their knowledge and skills at the disposal of people with disabilities.

\subsection{Research Methodologies Suited for Use in the Pragmatic Paradigm}

Because by definition the Pragmatic paradigm advocates the use of both qualitative and quantitative research methods according to need, research conducted within this paradigm draws on methodologies taken from both these fields. Commonly used methodologies include:
- Naturalist methodology
- Narrative inquiry
- Case study
- Phenomenology
- Ethnography
- Action Research
- Experimental methodology
- Quasi-experimental methodology
- Causal comparative methodology

\section{Conclusion}

From the discussions presented above and the literature reviewed, it should be clear to readers that paradigms as positions about epistemology, ontology and axiology, exert significant influences on the methodology to be used in a research project (Morgan, 2007). Because each paradigm is undergirded by specific assumptions as discussed earlier, choice of a paradigm for your research implies that the research will be nested in a particular epistemology, ontology, and axiology, and that these elements will therefore guide you towards a particular methodology. Thus, the choice of a paradigm implies a near certainty about particular methodologies that flow from that paradigm. This relationship is very important because the methodological implications of paradigm choice permeate, the research question/s, participants' selection, data collection instruments and collection procedures, as well as data analysis. Thus, research 
located in any of the four primary paradigms has a wide range of research methodologies to choose from. It is also worth noting, that it is quite possible to combine several research methodologies within one research paradigm. However, choice of the right methodologies needs to be informed by a good understanding of the different aspects of research paradigms discussed in this paper.

\section{References}

Alise, M. A., \& Teddlie, C. (2010). A continuation of the paradigm wars? Prevalence rates of methodological approaches across the social/behavioral sciences. Journal of Mixed Methods Research, 4(2), 103-126. https://doi.org/10.1177/1558689809360805

ARC. (2015). National Statement on Ethical Conduct in Human Research 2007 (Updated May 2015). Canberra: Australian Research Council.

Avramidis, E. \& Smith, B. (1999). An introduction to the major research paradigms and their methodological implications for special needs research, Emotional and Behavioural Difficulties, 4(3), 27-36. https://doi.org/10.1080/1363275990040306

Barnes, C (1992). Qualitative research: valuable or irrelevant? Disability, Research and Handicap, 7(2), 115-124.

Biesta, G. (2010). Pragmatism and the philosophical foundations of mixed methods research. In A. Tashakkori \& C. Teddlie (Eds.), Sage handbook of mixed methods in social \& behavioral research (2nd ed., pp. 95-118). Thousand Oaks, CA: Sage. https://doi.org/10.4135/9781506335193.n4

Bogdan, R. C. \& Biklen, S. K. (1998). Qualitative research in education: An introduction to theory and methods (3rd ed.). Needham Heights, MA: Allyn \& Bacon.

Bouma, G. D. \& G.B.J. Atkinson, G. B. J. (1995). A handbook of social science research, 2nd ed., Oxford: Oxford University Press.

Burns, B. R. (2000). Introduction to Research Methods, $4^{\text {th }}$ Edn. Frenchs Forest, Pearson education.

Candy. P.C. (1989). Constructivism and the study of'self-direction in adult learning. Studies in the Education of Adults, 21(2), 95-116. https://doi.org/10.1080/02660830.1989.11730524

Carpenter, C. (2013). Phenomenology and rehabilitation research. In P. Liamputtong (ed.) Research methods in health: Foundations for evidence based practice. (2nd ed., pp. 115-131). South Melbourne, Australia: Oxford University Press

Carr, W. L., \& Kemmis, S. (1986). Becoming critical: Education, knowledge and action research. London: Falmer.

Chalmers, D.J., Manley, D. \& Wasserman, R. (2005). Metametaphysics: New Essays on the Foundations of Ontology. Oxford University Press. Dorr, C.

Cohen, L; Manion, L. and Morrison, K. (2000). Research Methods in Education (5 th Ed.). London .

Comte, A . (1856). A general view of positivism. London: Smith Elder \& Co.

Cooksey, R. \& McDonald, G. (2011). Surviving and thriving in postgraduate research, Prahran, VIC, Tilde University Press.

Creswell, J. (1998). Qualitative inquiry and research design: Choosing among five traditions. Thousand Oaks, CA: Sage.

Creswell, J. W. (2007). Qualitative inquiry \& research design: Choosing among five approaches (2nd ed.). Thousand Oaks, CA: Sage Publications.

Creswell, J., \& Miller, D. (2000). Determining Validity in Qualitative Inquiry. Theory Into Practice, 19(3), 124-130. https://doi.org/10.1207/s15430421tip3903_2

Creswell, J.W. (2003). Research design: Qualitative, quantitative, and mixed methods approaches. (2nd ed.) Thousand Oaks: Sage.

Davidson, D. (2000). A Coherence Theory of Truth and Knowledge. In S. Bernecker, \& F. Dretske (Eds.). Knowledge, readings in contemporary epistemology, Oxford Press.

Denzin, N.K. \& Lincoln, Y.S. (2000). Handbook of qualitative research, Sage, London. Sage.

Erlandson, D., Harris, E. Ll, Skipper, B. L. \& Allen, S. D. (1993). Doing naturalistic inquiry: a guide to methods, London: Sage.

Fadhel K. 2002, Positivist and Hermeneutic Paradigm, A Critical Evaluation under their Structure of Scientific 
Practice, The Sosland Journal, 21-28.

Finnis, J. (1980). Natural Law and Natural Rights. Oxford: Clarendon Press.

Foucault M (1982). The Subject and Power. Afterword to Dreyfus HL \& Rabinow P. Michel Foucault: Beyond Structuralism and Hermeneutics. Brighton, Harvester.

Foucault M 1987 [1984]. The Ethic of Care for the Self as a Practice of Freedom - An Interview with Michel Foucault. Philosophy and Social Criticism, 12, 112-131. https://doi.org/10.1177/019145378701200202

Furlong, M. (2013). 'Clear at a distance. Jumbled up Close: Observation, immersion and reflection in the process that is creative research. In P. Liamputtong (ed.) Research methods in health: Foundations for evidence based practice. (2nd ed., pp. 144-158). South Melbourne, Australia: Oxford University Press

Gage, N.L. (1989). The paradigm wars and their aftermath: A historical sketch of research on teaching since 1989. Educational Researcher, 18(7), 4-10.

Gomm, R.; Hammersley, M. \& Foster, P. (2000). Case study and generalization, in: Case study method, R. Gomm, M. Hammersley and P. Foster, eds, London: Sage, pp. 98-115.

Guba, E. G. (1981). Criteria for assessing the trustworthiness of naturalistic inquiries. Educational Communication and Technology Journal, 29(1981), 75-91.

Guba, E.G. \& Lincoln. Y.S. (1988). Do inquiry paradigms imply inquiry methodologies? In D.M. Fetterman. (ed.) Qualitative approaches to evaluation in education: The silent scientific revolution. (pp. 89-115), London, Praeger.

Guba, E.G. \& Lincoln. Y.S. (1989). What is This Constructivist Paradigm Anyway? in Fourth Generation Evaluation, London: Sage Publications, 79-90.

Guba, E. (1990). The Paradigm Dialog, Sage, California.

Guba, E. G. \& Lincoln, Y. S. (1994). Competing paradigms in qualitative research. In Denzin, N.K. \& Lincoln, Y.S. Handbook of qualitative research, 3rd Edn. (pp. 105 - 117). California: Sage.

Guba, E. G. \& Lincoln, Y (2005) ' Paradigmatic controversies, contradictions \& emerging confluences' in The Sage Handbook of Qualitative Research, 3rd Edn. California: Sage.

Joppe, M. (2000). The Research Process. Retrieved 5 August, 2018, from: http://www.ryerson.ca/ mjoppe/rp.htm

Keeves, J. P. (1997). Educational research methodology and measurement. Cambridge: Cambridge University Press.

Kirk, J., \& Miller, M. L. (1986). Reliability and validity in qualitative research. Beverly Hills: Sage Publications. https://doi.org/10.4135/9781412985659

Kuhn, T. S. (1962). The structure of scientific revolutions. ( $1^{\text {st }}$ Edn). Chicago, IL: University of Chicago Press.

Kuhn, T. (1970). Postscript 1969. In T. Kuhn, The structure of scientific revolutions (2nd ed., pp. 174-210). Chicago: University of Chicago Press.

Lather, P. (1986). Research as praxis. Harvard Educational Review, 56(3), 257-277. https://doi.org/10.17763/haer.56.3.bj2h231877069482

Lincoln, Y. S. \& Guba, E. G. (Eds. 1985). Naturalistic Inquiry. Thousand Oaks: Sage.

Lincoln, Y. S. (1995). Emerging criteria for quality in qualitative and interpretive research, Qualitative Inquiry, 1 , 275-289. https://doi.org/10.1177/107780049500100301

Lincoln, Y. S. \& Guba, E. G. (2000). Paradigmatic controversies, contradictions, and emerging confluences. In Denzin, N.K. \& Lincoln, Y.S. (2000). Handbook of qualitative research, London: Sage, Chapter 6, 163 - 188.

Mackenzie, N. \& Knipe, S. (2006). Research dilemmas: paradigms, methods and methodology. Issues In Educational Research, 16, 1-15.

Mertens, D. M. (2015). Research and Evaluation in Education and Psychology. $4^{\text {th }}$ Edn. Los Angeles: Sage.

Merriam, S. B. (1998). Qualitative research and case study applications in education, San Francisco: Jossey-Bass.

Mill, J. S. (1969). Utilitarianism. In Essays on Ethics, Religion, and Society, edited by J. M. Robson. Vol. 10 of Collected Works of John Stuart Mill. Toronto: University of Toronto Press, pp. 203-259.

Moreno, J. (1947). Contribution of sociometry to research methodology in sociology. American Sociological Review, 12(6), pp. 287 - 292. https://doi.org/10.2307/2086518 
Morgan, D.L. (2007). Paradigms Lost and Pragmatism Regained: Methodological Implications of Combining Qualitative and Quantitative Methods. Journal of Mixed Methods Research, 1(1), 48-76.

Moustakas, C. (1994). Phenomenological Research Methods. Thousand Oaks, CA: Sage. https://doi.org/10.4135/9781412995658

Polkinghorne, D. E. (1988). Narrative knowing and the human sciences. Albany, NY. State University of New York. Press.

Myrdal, G. (1969). Objectivity in Social Research, London: Pantheon Books, New York.

Neurath, O. (1973). The scientific conception of the world: The Vienna Circle. In M. Neurath \& R. Cohen (Eds.), Empiricism and sociology. Boston: Reidel. https://doi.org/10.1007/978-94-010-2525-6

Patton, M. Q. (1990). Qualitative evaluation and research methods, 2nd ed. Newbury Park: Sage.

Prochaska, F. (2017). Internal and external validity. San Jose, CA: San Jose State University. Accessed online on 7 August 2017 at: http://www.sjsu.edu/people/fred.prochaska/courses/ScWk240/s1/ScWk-240-Week-5-2nd-Set-Slides---Internal-a nd-External-Validity.pdf

Punch, K. (2005). Introduction to Social Research: Quantitative and qualitative approaches, London: Sage Publications.

Putnam, H. (2012). 'How to Be a Sophisticated "Naive Realist"'. In 'Philosophy in an Age of Science'. Harvard University Press, Cambridge, Mass.

Scheffler, S. (1982). The Rejection of Consequentialism: A Philosophical Investigation of the Considerations Underlying Rival Moral Conceptions. Oxford: Clarendon Press.

Schwandt, T.A. (1997). Qualitative Inquiry: A dictionary of terms. Thousand Oaks,CA: Sage.

Scotland, J. (2012). Exploring the philosophical underpinnings of research: Relating ontology and epistemology to the methodology and methods of the scientific, interpretive, and critical research paradigms. English Language Teaching, 5(9), pp. 9-16. https://doi.org/10.5539/elt.v5n9p9

Scott. D. \& Usher, R. (2004). Researching education: Data, methods, and theory in educational enquiry. New York: Continuum.

Searle, J. R. (2015). 'Seeing Things as They Are; A Theory of Perception', Oxford University Press. https://doi.org/10.1093/acprof:oso/9780199385157.001.0001

Shenton, A. K. (2004). Strategies for ensuring trustworthiness in qualitative research projects. Education for Information, 22, 63 - 75. https://doi.org/10.3233/EFI-2004-22201

Sidgwick, H. (1907). The Methods of Ethics. 7th ed. London: Macmillan.

Silverman, D. (2000). Doing qualitative research: a practical handbook, London: Sage.

Skidmore, D. (1996). Towards an integrated theoretical framework for research into special educational needs. European Journal of Special Needs Education, 11(1), 33-47. https://doi.org/10.1080/0885625960110103

Slavin, R. E. (1984). Research methods in education: A practical guide. Englewood Cliffs, NJ: Prentice-Hall.

Slote, M. (1985). Common-Sense Morality andConsequentialism. London: Routledge \& Kegan Paul.

Smith. J. K. \& Heshusius, L. (1986). Closing down the conversation: The end of the qualitative/quantitative debate among educational inquirers. Educational Researcher, (150), 4-12.

Strauss, A., \& Corbin, J. (1990). Basics of qualitative research: Grounded theory procedures and techniques. NewPark, CA: Sage Publications, Inc.

Tashakkori A \& Teddlie C. (Eds). (2003a). Handbook of Mixed Methods in Social \& Behavioral Research, Sage, California

Tashakkori, A., \& Teddlie, C. (2003b). Major issues and controversies in the use of mixed methods in the socialand behavioral sciences. In A. Tashakorri \& C. Teddlie (Eds.), Handbook of mixed methods in social \& behavioral research (pp. 3-50). Thousand Oaks, CA: Sage.

Taylor, J. \& Bogdan, R. (1984). Introduction to qualitative research methods: the search for meanings. Michigan, Wiley. 